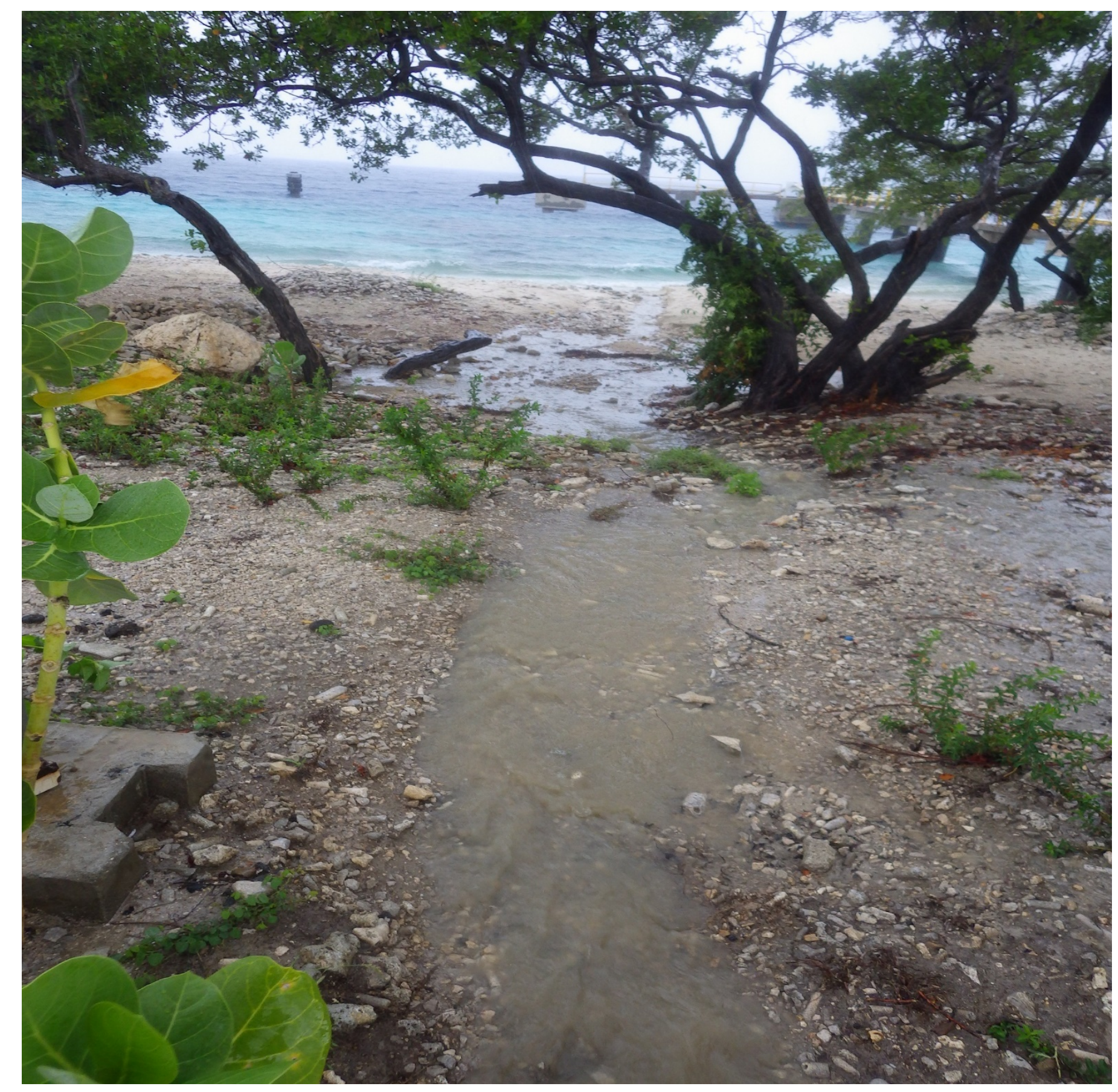

Impact of terrestrial erosion on coral reef health at Bonaire: a plea for nature-inclusive "watershed-to-reef" based coastal management

Author(s): $\quad$ Matthijs van der Geest ${ }^{1}$, Erik Meesters ${ }^{1}$, Sander Mücher ${ }^{2}$

1: Wageningen Marine Research

2: Wageningen Environmental Research
Wageningen

University \& Research

report C055/20 


\section{Impact of terrestrial erosion on coral reef health at Bonaire: a plea for nature-inclusive "watershed-to-reef" based coastal management}

Author(s): $\quad$ Matthijs van der Geest ${ }^{1}$, Erik Meesters $^{1}$, Sander Mücher ${ }^{2}$

1: Wageningen Marine Research

2: Wageningen Environmental Research

The authors would like to acknowledge funding from the Wageningen University Knowledge Base programme: KB36 Biodiversity in a Nature Inclusive Society (project number KB-36-005-002) - that is supported by finance from the Dutch Ministry of Agriculture, Nature and Food Quality 
Keywords: overgrazing, ground cover, erosion hazard, sediment, terrestrial run-off, nature-inclusive coastal management, Bonaire, Caribbean

This report can be downloaded for free from https://doi.org/10.18174/524688

Wageningen Marine Research provides no printed copies of reports

Wageningen Marine Research is ISO 9001:2015 certified.

Photo cover: Matthijs van der Geest

(C) Wageningen Marine Research

Wageningen Marine Research, an institute within the legal entity Stichting Wageningen Research (a foundation under Dutch private law) represented by Dr. M.C.Th. Scholten, Managing Director

KvK nr. 09098104,

WMR BTW nr. NL 8113.83.696.B16.

Code BIC/SWIFT address: RABONL2U

IBAN code: NL 73 RABO 0373599285

Wageningen Marine Research accepts no liability for consequential damage, nor for damage resulting from applications of the results of work or other data obtained from Wageningen Marine Research. Client indemnifies Wageningen Marine Research from claims of third parties in connection with this application. All rights reserved. No part of this publication may be reproduced and / or published, photocopied or used in any other way without the written permission of the publisher or author. 


\section{Contents}

Impact of terrestrial erosion on coral reef health at Bonaire: a plea for nature-inclusive "watershed-to-reef" based coastal management

$1 \quad$ Introduction

$2 \quad$ Materials and Methods $\quad 7$

$\begin{array}{lll}2.1 & \text { Study area } & 7\end{array}$

2.2 Conceptual framework erosion hazard per watershed $\quad 8$

\begin{tabular}{ll}
2.3 & Monitoring of benthic community composition \\
\hline
\end{tabular}

$\begin{array}{ll}2.4 & \text { Identification of watersheds }\end{array}$

$\begin{array}{ll}2.5 & \text { Identification of erosion hazard per watershed } \\ 2.6 & 10\end{array}$

$\begin{array}{ll}2.6 & \text { Data selection } \\ 2.7 & 10\end{array}$

$\begin{array}{ll}2.7 & \text { Statistical analysis } \\ \end{array}$

3 Results $\quad 12$

3.1 Identified watershed properties $\quad 12$

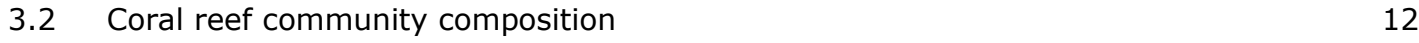

$\begin{array}{lll}3.3 & \text { Watershed-reef health relationship } & 13\end{array}$

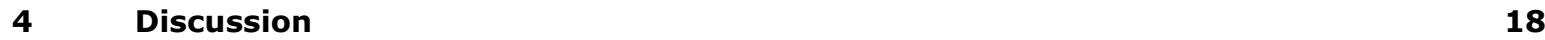

$\begin{array}{llr}4.1 & \text { Methodological aspects } & 19\end{array}$

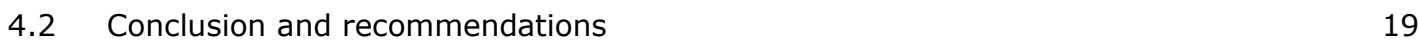

$5 \quad$ Acknowledgements $r 20$

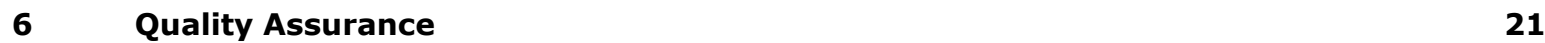

$\begin{array}{lr}\text { References } & 22\end{array}$

$\begin{array}{lr}\text { Justification } & 24\end{array}$

Annex 1 Identified watersheds, water flows, and run-off sites into the sea for Bonaire based on DEM

Annex 2 Slope (in degrees) per pixel (10 $\mathrm{m}$ resolution) for Bonaire based on DEM

Annex 3 Fraction vegetation ground cover per pixel (10m resolution) for Bonaire, based on MVC-NDVI

Annex 4 Erosion hazard per pixel (10m resolution) for Bonaire

Annex 5 Mean erosion hazard per watershed for Bonaire

Annex 6 Percentage coral cover at the lower terrace reef zone at the leeward reef of Bonaire in relation to watershed-specific mean erosion hazard and water flows

Annex 7 Percentage coral cover at the upper drop-off reef zone at the leeward reef of Bonaire in relation to watershed-specific mean erosion hazard and water flows 


\section{Summary}

Coral reefs are rapidly degrading worldwide, due to a combination of global and local stressors. While global stressors, such as ocean warming, cannot be managed, management of local stressors can increase the resilience of coral reefs to these global stressors. One such local stressor is overgrazinginduced terrestrial erosion causing sediment and nutrient run-off to coastal waters, which is associated with coral mortality and changes in benthic community composition. In this study we assessed the link between watershed-specific erosion hazard and coral reef health, using the coral reefs on the west coast of Bonaire, Caribbean Netherlands, as a case study. We first identified watersheds, waterflow and run-off sites into the sea based on a digital elevation model. Next, for each watershed we determined the mean erosion hazard (a proxy for the degree of terrestrial run-off based on slope and ground vegetation cover). Subsequently, we used multiple regression models to investigate whether mean erosion hazard of the nearest upstream watershed, and distance to the nearest upstream runoff point explained variation in marine benthic community composition at two depth zones ( $5 \mathrm{~m}$ and $\sim 10 \mathrm{~m}$ ). We found a negative relationship between mean erosion hazard and coral cover (a proxy for coral reef health) at $5 \mathrm{~m}$ depth, but no such effect at $10 \mathrm{~m}$ depth. In addition, we found a positive relationship between mean erosion hazard and sand cover (a proxy for sediment run-off) for both depth zones, and a small but significant quadratic effect of mean erosion hazard on algae cover (a proxy for nutrient run-off) at $5 \mathrm{~m}$ depth. Moreover, distance to the nearest upstream terrestrial run-off point was positively related with coral cover at $10 \mathrm{~m}$ depth, and negatively related with sand cover at $10 \mathrm{~m}$ depth. Our results provide direct evidence for a negative relationship between watershed-specific erosion hazard and coral reef health, and highlight the need for a nature-inclusive "watershed-to-reef" based coastal management approach that integrates terrestrial and marine conservation to preserve the island's valuable coral reef and related ecosystem services. 


\section{Introduction}

Coral reefs provide a wealth of ecosystem services, including food and resource security, tourism, coastal protection, socio-cultural services, and the highest biodiversity in the oceans (Moberg \& Folke 1999). Yet, coral reefs and associated ecosystem services are in rapid decline worldwide, due to a variety of local and global stressors (Hughes et al. 2003, Kennedy et al. 2013). While local stressors, such as overfishing and reduced water quality, have been the major drivers of coral reef degradation for centuries, more recent climate change-induced stressors, such as bleaching, ocean acidification, sea level rise, and intensified storms, nowadays impose a global threat to coral reefs (Webster et al. 2005, Hoegh-Guldberg et al. 2007, Hughes et al. 2017). Clearly, immediate global efforts to drastically reduce greenhouse gas emissions that cause climate change, are essential, to prevent further degradation of coral reefs. Yet, effective management of local stressors can also greatly help in maintaining and increasing coral reef resilience and in limiting the long-term damage from bleaching and other climate-related effects (Hughes et al. 2003, Kennedy et al. 2013, Scheffer et al. 2015).

One of the greatest local threats to coral reefs worldwide is ever increasing land-based inputs of sediment, nutrients and pollutants, due to human-induced alterations in watersheds (e.g. clearing of forest, increased agriculture, overgrazing, urbanization, land use) (Fabricius 2005, Risk 2014). Coral reefs experiencing high land-based run-off typically have fewer coral species, less live coral cover, lower rates of calcification and photosynthesis, reduced coral recruitment and survival, increased competition with macroalgae, and increased susceptibility to coral diseases or climate impacts (Fabricius 2005, Risk 2014).

The degree of land-based run-off is determined by watershed specific characteristics, including: soil type, slope, vegetation ground cover, and land use (Roberts et al. 2017 and references therein). Vegetation ground cover traps surface sediments, increases infiltration of water into the soil, and slows water flow, therefore decreasing the amount of terrestrial run-off (Bartley et al. 2014). In turn, land use which changes vegetation cover or alters soil surface structure, such as through agriculture or construction of concrete roads, can impact land-based run-off and associated soil erosion (Álvarez-Romero et al. 2011, Risk 2014). As a result, the types of management actions needed to maintain coral reef resilience will differ spatially, depending on the characteristics of each watershed-to-reef system. Although identification of where and which local stressor plays a dominant or minor role in a specific watershed-to-reef system is difficult, it is needed for efficient allocation of limited resources for coral reef conservation (Stoms et al. 2005).

Within the last two decades, a growing number of studies have emerged elucidating the need to explicitly incorporate conservation of upland watersheds in coral reef conservation planning (Klein et al. 2010, Álvarez-Romero et al. 2011, Risk 2014, Roberts et al. 2017, Carlson et al. 2019) and a number of models have been developed to identify erosion threats (Álvarez-Romero et al. 2014), or to integrate threat management between ecosystems (Klein et al. 2010, Klein et al. 2014, Oleson et al. 2017, Delevaux et al. 2018). But, studies that have investigated the direct link between watershedspecific terrestrial degradation and coral reef health are still limited. A significant positive relationship between watershed vegetation cover and reef health has been found in coral reefs in Hawaii, though the strength of this relationship varied with reef exposure to surf conditions (Rodgers et al. 2012). Improvements in terrestrial conservation in Fiji were estimated to result in a $10 \%$ improvement of coral reef condition (Klein et al. 2014). In the Caribbean island of Bonaire, mean percent cover of vegetative land was positively related with deep (>10 m) coral cover (Roberts et al. 2017).

The leeward fringing reefs of Bonaire (Southern Caribbean) are known to display a wide range of ecological degradation from almost pristine configurations to reefs that are approaching full functional collapse (de Bakker et al. 2017, de Bakker et al. 2019). This spatial heterogeneity in coral reef degradation has been attributed to spatial variation in a variety of local disturbances, both at sea and on land (Roberts et al. 2017, de Bakker et al. 2019), which suggests that management of these local stressors, once identified, can benefit coral reef health. The island has a long history of terrestrial degradation, with invasive herbivores introduced in the $16^{\text {th }}$ Century, and widespread tree clearance in the early 1900s (Freitas et al. 2005). Such changes are recognized as local threats of Bonaire's marine ecosystems, as they promote erosion-related terrestrial run-off (Roberts et al. 2017). 
In this study we assess the direct link between watershed-specific erosion hazard and downstream coral reef health, using the leeward reefs of Bonaire, as a case study. We use a digital elevation model to identify watersheds, waterflow and run-off sites into the sea. Next, for each watershed we determine mean erosion hazard (a proxy for the degree of terrestrial run-off based on slope and ground vegetation cover). Subsequently, we use multiple regression models to investigate whether mean erosion hazard of the nearest upstream watershed, and distance to the nearest upstream run-off point explains variation in reef health (i.e. coral cover, sand cover, and algae cover), at two depth zones ( $\sim 5 \mathrm{~m}$ and $\sim 10 \mathrm{~m}$ ). This study thus provides insights on whether coral reef conservation at Bonaire can be improved by watershed-based erosion control, and contributes to costeffective coral reef management by identifying watersheds where the effect of erosion control will be maximized in terms of improved coral reef health. 


\section{Materials and Methods}

\section{$2.1 \quad$ Study area}

Bonaire, Caribbean Netherlands, is a special municipality of the Kingdom of the Netherlands, situated in the Southern Caribbean $\left(12^{\circ} 9 \mathrm{~N}, 68^{\circ} 16^{\prime} \mathrm{W}\right.$, Fig.1), with an surface area of $294 \mathrm{~km}^{2}$. Bonaire's terrestrial ecosystem is made up of tropical dry-forest, which receives an average of $500 \mathrm{~mm}$ of rainfall per year (Borst \& De Haas 2005). Rainfall is highest between October and March, and falls predominantly in short, heavy showers. The soil types at Bonaire, mainly consist of Neogene limestone and basalt pillow lava (Washikemba Formation) (Freitas et al. 2005). Water retention capacity of these soil types is poor so that most rainfall quickly runs off into coastal waters (Roos 1971). As a result of the prevailing easterly trade wind, the predominant water current movement on the leeward side of Bonaire runs from south to north. With no permanent above ground rivers or streams, diffuse terrestrial run-off with rainfall, and to a smaller extent by wind, is expected to be the major input of sediment and nutrients into Bonaire's coastal waters.

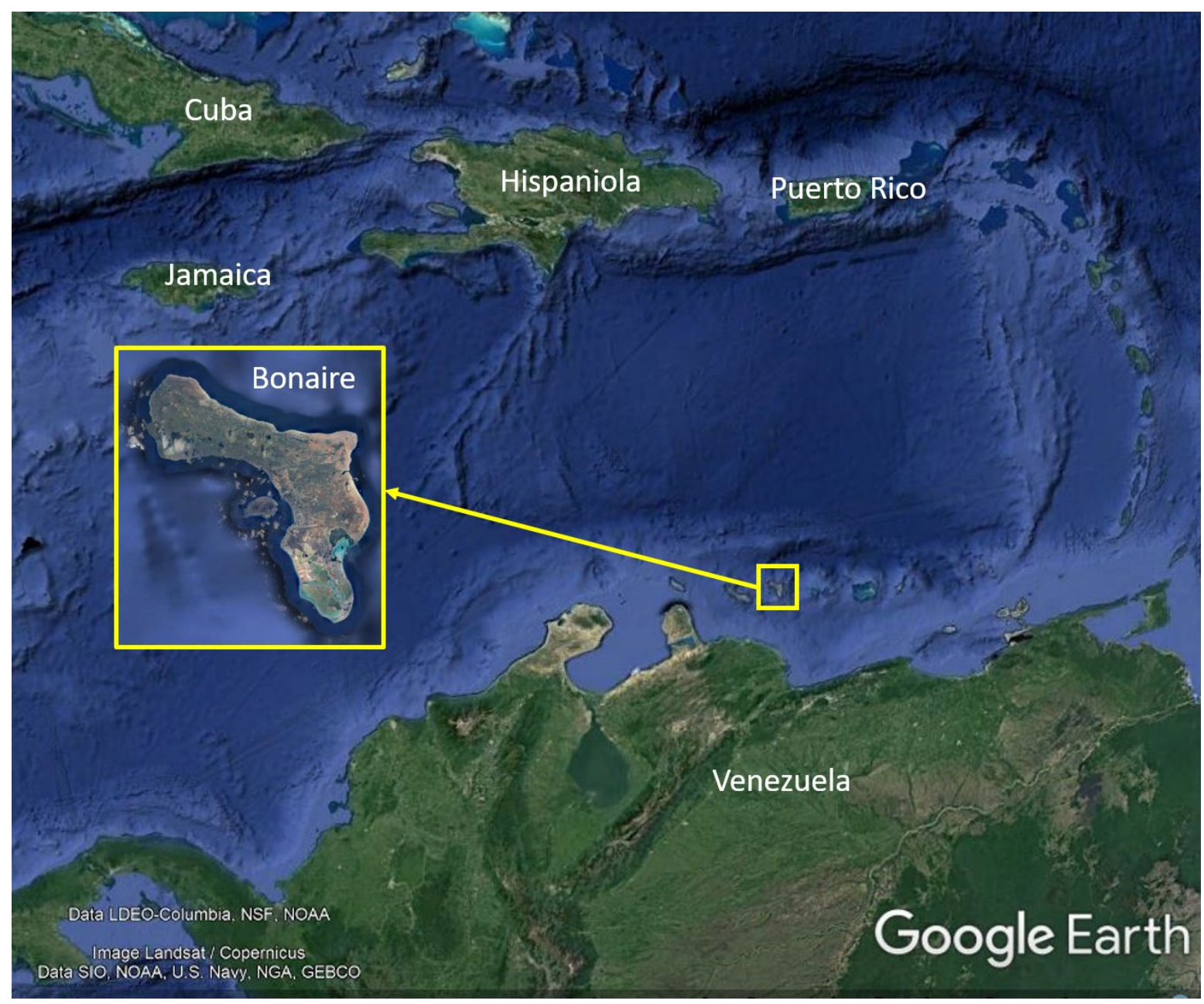

Fig. 1. Location of Bonaire, Caribbean Netherlands. Google Earth Pro 2020 imagery date 14 December 2015 . 


\subsection{Conceptual framework erosion hazard per watershed}

Coral reef health is impacted by sediment and nutrient run-off, which originates from associated watersheds. Rainfall increases sediment run-off rates through increasing surface water run-off which transports sediments from the terrestrial ecosystem. Steeper slopes are associated with increased run-off. Sediment run-off is decreased through the presence of vegetation, whose root systems anchor sediment and slow water flow. Soil type and presence of rivers and streams also impacts sediment run-off. However, because soil type at Bonaire mainly consist of Neogene limestone and basalt pillow lava, which both are characterized by low water retention capacity, and as permanent streams and rivers are absent, they are not included in our framework (Fig. 2).

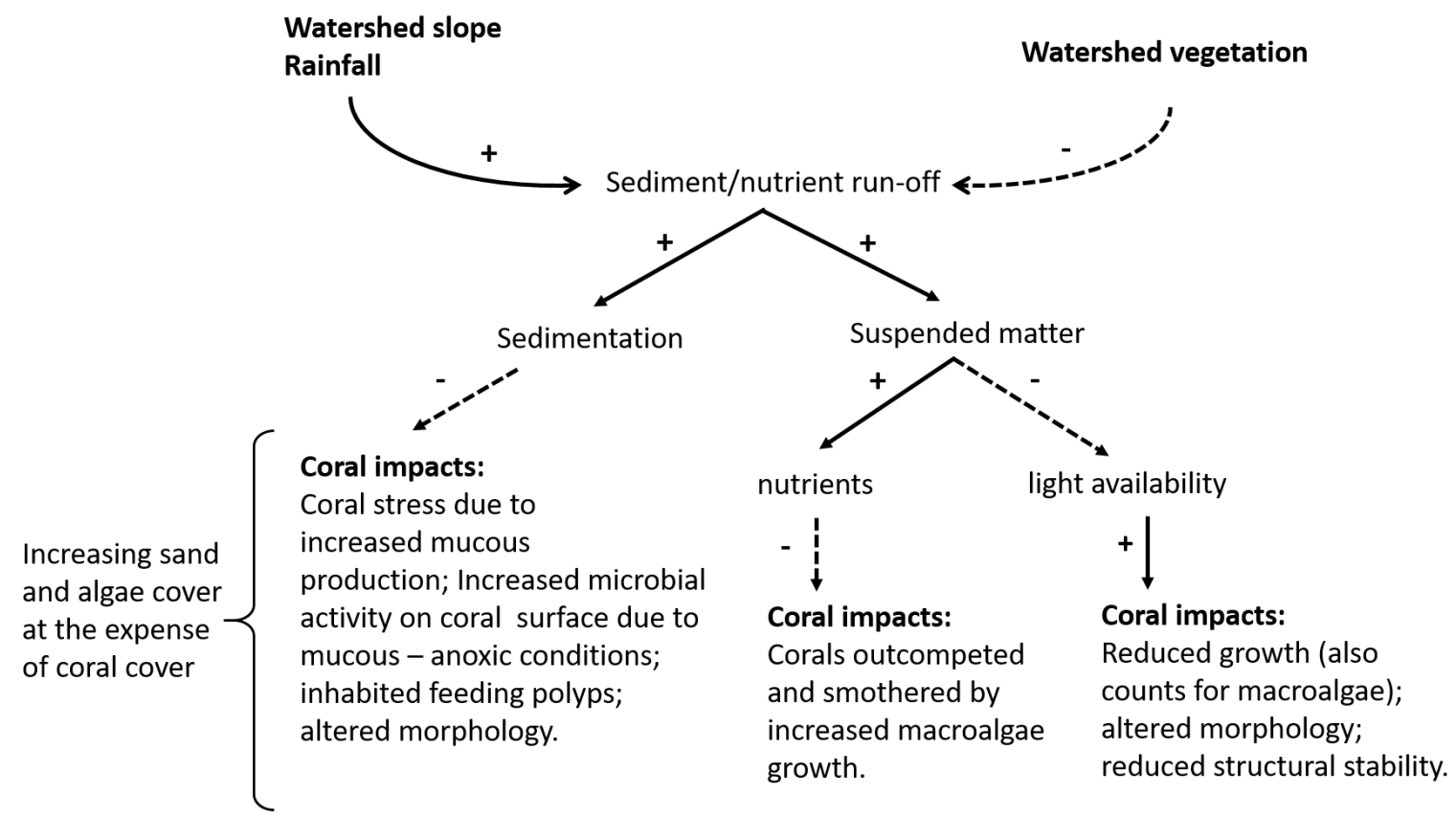

Fig. 2. Conceptual framework of impacts of locally relevant watershed characteristics on sediment and nutrient run-off, and therefore reef health at Bonaire. Modified after Roberts et al. (2017).

\subsection{Monitoring of benthic community composition}

Extensive benthic surveys were conducted in the shallow fringing reef habitat of the southernCaribbean island of Bonaire. These surveys were limited to the leeward side of Bonaire, where reefs and human activities are concentrated, and where impact of coastal erosion on reef community functioning are expected to be most severe (de Bakker et al. 2019). A total of 115 sites were assessed, separated by a predefined distance of $\sim 500 \mathrm{~m}$ and covering the leeward reef stretch of Bonaire and satellite island of Klein Bonaire. At each site, benthic cover was monitored in the lower terrace zone (LT, 5-7 m depth) and the drop-off zone (DO, 8-12 m depth) along fixed 10-m transect lines ( 2 per zone) positioned parallel to the orientation of the reef front and separated by $40 \mathrm{~m}$. These benthic surveys were conducted between September and December in 2017.

The contribution of each benthic component (both biotic and abiotic) was quantified in situ as the total distance (to the nearest $\mathrm{cm}$ ) covered directly below the main transect line. Benthic organisms were identified in situ and to the finest taxonomic resolution (i.e. to species level for corals, to genus level for most macroalgae, etc.). For general site characterization, all encountered benthic components were grouped in major functional categories, as defined by De Bakker et al. (2017). The following categories were assigned for benthic cover: live hard (scleractinian) coral (including Millepora spp.); algal turfs (filamentous assemblages $<1 \mathrm{~cm}$ in height); benthic cyanobacterial mats; fleshy macroalgae (almost exclusively Lobophora spp. and Dictyota spp.); sponges, further separated into massive and encrusting growth forms; crustose coralline algae; bare substratum including recently dead coral, coral rubble and pavement; and sand. Gorgonians, hydrocorals (milleporids), tunicates 
(with the exception of Trididemnum solidum in 1989 at IV-20 m) and other invertebrates were extremely rare in the photographs and grouped under the category "other". For this study, we only used proportion hard coral cover (used as proxy for coral health), proportion sand cover (proxy for sediment run-off), and proportion algal cover (i.e. proportion algal turfs and fleshy macroalgae were pooled and used as a proxy for nutrient run-off) for further analysis. Proportion cover of each of these three categories per transect were averaged per depth zone, per site prior to statistical analysis.

\subsection{Identification of watersheds}

Based on an improved ASTER Digital Elevation map (DEM) with $10 \mathrm{~m}$ resolution (see Fig. 3) and ArcGIS hydrology tools, watersheds, slope (in degrees), water flows and locations of sediment and nutrient run-off into the sea per watershed were determined for the entire island of Bonaire (Annex 1$)$.

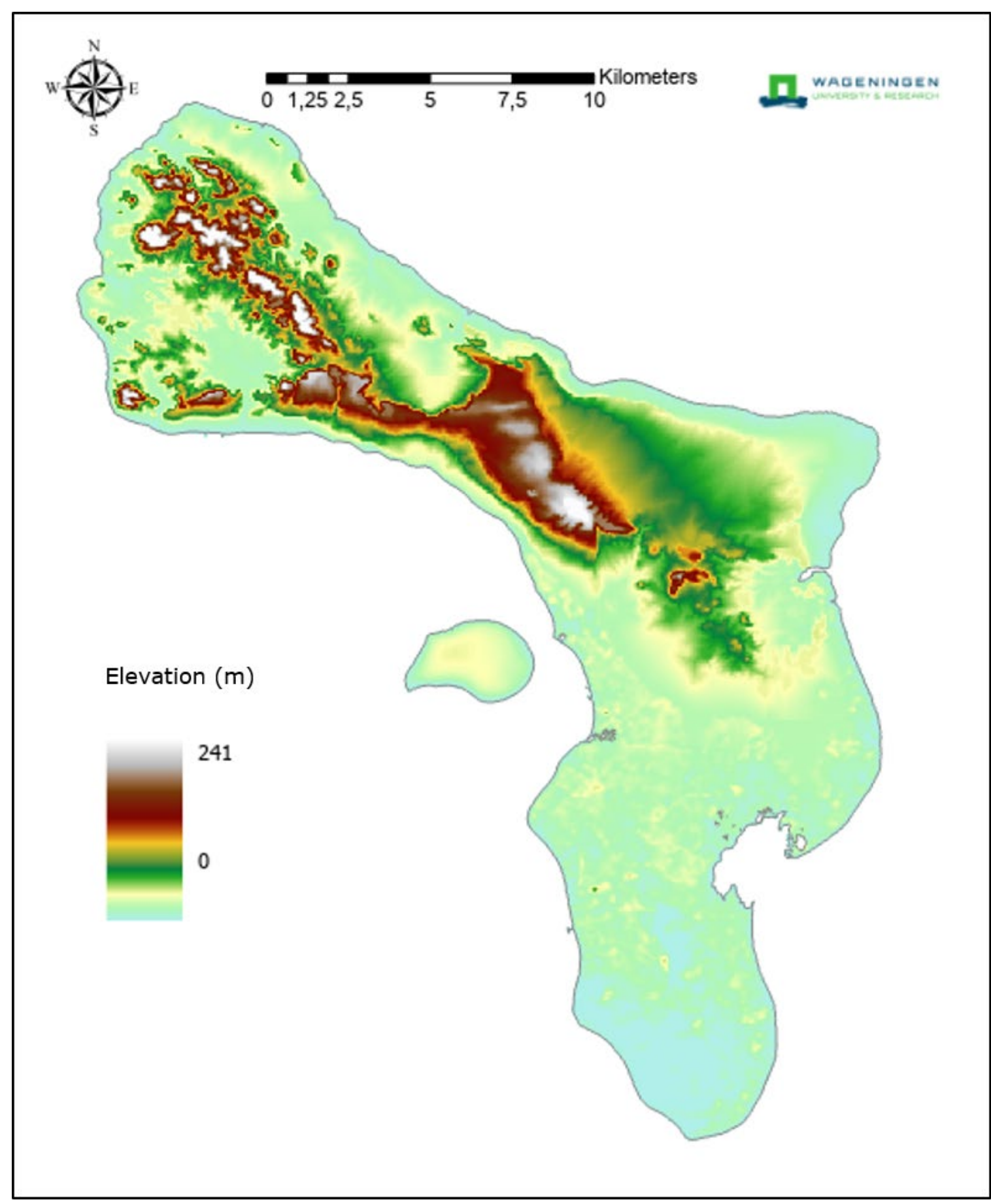

Fig. 3. Improved ASTER DEM for Bonaire with a 10 meter spatial resolution and 1 meter height resolution (source: Mücher et al. 2017)). 
Mücher et al. (2017) improved the ASTER DEM for Bonaire to make a new bathymetric model. They converted the ASTER DEM to contour lines, while they added extra height points for the lowlands of Bonaire, as well as extra measured sea depth points (collected in a separate campaign) to calculate a new bathymetric model that interpolated the improved DEM with the measured sea depth points.

\subsection{Identification of erosion hazard per watershed}

We assumed that watershed-specific erosion risk and subsequent terrestrial run-off would increase as a function of slope and decrease as a function of vegetation cover. Previous studies showed that there was no spatial variation in rainfall across the small island of Bonaire (Roberts et al. 2017). Therefore, we assumed that the effect of rainfall on erosion hazard was similar across all watersheds of Bonaire. Since vegetation cover is minimal at the end of the dry season (i.e. August), vegetation cover in August can be used to identify areas that are prone to erosion risk. As such, we used Copernicus sentinel images (processed by ESA), from Bonaire that were taken at 7 July and 21 August 2018 with very limited cloud coverage. But still a combination of the two sentinel images was needed to reduce cloud cover even more, to determine the Normalized Difference Vegetation Index (NDVI, a commonly used proxy for vegetation cover) at the end of the dry season. Using ArcGIS, NDVI was calculated per pixel (10 m resolution) as NDVI $=($ NIR-RED)/(NIR+ RED) where RED and NIR are the digital numbers (DN) corresponding to the spectral values in the red and near-infrared regions, respectively. To process NDVI data from the two sentinel images into one image, we followed a Maximum Value Composite (MVC) procedure, where on a pixel-by-pixel basis, only the highest NDVI value is retained for each pixel location. Likewise, the DEM was used to determine the slope (in degrees) for each pixel. To determine the fraction of ground covered by green vegetation per pixel (fraction vegetation cover), we first extracted the highest NDVI value (NDVI $\max$ ) and the lowest NDVI value (NDVI $\min$ ) from the Bonaire dataset. Next, we assumed that the pixel with the highest NDVI value, which was located in a dense mangrove forest, reflected $100 \%$ vegetation cover, and that the pixel with the lowest NDVI value, which was located on a bare piece of land, reflected $0 \%$ vegetation cover. Next, we could calculate the fraction vegetation cover per pixel as fraction cover $=\left(N D V I-N D V I_{\min }\right) /\left(N D V I_{\max }-\right.$ $\left.N D V I_{\text {min }}\right)$. As run-off requires a slope, we assumed that erosion hazard was zero for locations that were flat (pixels with slope $=0$ degrees). For pixels with slope $>0$ degrees, the fraction bare soil (1-fraction cover) was used as a proxy for erosion hazard. The erosion hazard was expressed per pixel (of 10 by 10 meter) in values between 0 and 1 . Subsequently, mean erosion hazard per watershed was estimated by averaging the erosion hazard values of the pixels within that specific watershed.

\subsection{Data selection}

The inaccuracy of available digital terrain maps (DTMs) did not allow to calculate catchment areas and water flows for Klein Bonaire, which is relatively flat island (see Fig. 3). As a result, we could not determine erosion hazard for Klein Bonaire. Likewise, the Southern part of Bonaire mainly consisted of salt pans (i.e. water), for which we could not determine the erosion hazard. Therefore, benthic cover data collected at the 21 sites located around Klein Bonaire and at the 23 sites located next to the salt pan area in the South of Bonaire were excluded from further analysis, leaving a total sample size of $\mathrm{N}=71$ benthic sites that were used for analysing the relationships between benthic cover and watershed-specific properties of the nearest upstream watershed. Moreover, run-off from watershed 52 and 54 ended up in a small coastal inlet where run-off from both watersheds was mixed and disposed to the reef. As a result, the effect of each of these two watersheds on benthic cover could not be separated. Therefore, we considered these two watersheds as one single watershed, for which we used the sum of the surface area of watershed 52 and 54 as surface area, and the mean of the mean erosion hazard calculated for 52 and 54 as the mean erosion hazard when analysing the relationships between benthic cover and the properties of this watershed. 


\subsection{Statistical analysis}

A Pearson correlation analysis was performed to evaluate the relationship between mean coral, sand and algae cover per depth zone. Linear modeling was used to look for significant differences between coral, sand and algae cover between depth zones. We used multiple regression models to investigate whether watershed-specific properties (i.e. mean erosion hazard, surface area) of the nearest upstream watershed, and distance to the nearest upstream run-off point source, explained variation in the proportion of benthic cover (i.e. hard coral, sand, algae) at a specific reef site, for each depth zone (i.e. lower terrace and drop-off). We included surface area of the nearest upstream watershed as a covariate in the model, as we assumed a positive relationship between the surface area of a watershed and the amount of sediment and nutrient discharged into the sea during events of rainfall, with subsequent effects on marine benthic cover. Likewise, distance to the nearest upstream run-off point source was included as a covariate, as we assumed the impact of sediment and nutrient run-off on benthic cover to decrease as a function of distance to nearest upstream run-off point source. As we did not expect any statistical interactions between our explanatory variables, only main effects were taken into account in the model. Model selection was based on Akaike's information criterion adjusted for small sample size (AICc) (Burnham \& Anderson 2002). Parameter estimates, standard errors, $t$ values, and $P$-values of the most parsimonious model are reported, with the most parsimonious model being the model with the fewest parameters within $2 \Delta \mathrm{AIC}_{\mathrm{c}}$ of the top model (Burnham \& Anderson 2002). Given the oligotrophic waters of the Caribbean Sea, we expected algae cover to be positively related to sediment and nutrient run-off up to a certain threshold level, after which run-off may have a negative effect on macroalgae cover, due to reduced light conditions (see also Fig. 2). Therefore, we also included a quadratic term for mean erosion hazard in the model explaining variation in algal cover. This resulted in the following multiple regression models:

Coral cover $\sim$ erosion hazard + surface area + distance to run-off

Sand cover $\sim$ erosion hazard + surface area + distance to run-off

Algal cover $\sim$ erosion hazard + erosion hazard ${ }^{2}+$ surface area + distance to run-off

where erosion hazard (a continuous variable running from 0 to 1 ) refers to the mean erosion hazard determined for the nearest upstream watershed, surface area refers to the surface area (ha) of the nearest upstream watershed, and distance to run-off refers to the distance $(\mathrm{m})$ to the nearest upstream run-off point source. Prior to statistical analysis, the proportion of coral, sand and algal cover was fourth-root-transformed to obtain normality. Exploration of the model residuals with variogram plots indicated that there was no need to account for spatial autocorrelation. Assumptions for linear regression were confirmed visually. $P$-values $<0.05$ were considered significant. All analyses were performed in program $\mathrm{R}$ ( $\mathrm{R}$ Core Team, 2018, version 3.5.0). Maps were created using the free and open source QGIS 3.10. 


\section{Results}

\subsection{Identified watershed properties}

We identified 69 watersheds (numbered from 1 to 69) for Bonaire (see Annex 1). For each of these watersheds, water flow and run-off sites into the sea were identified (see Annex 1). Slope per pixel (10 $\mathrm{m}$ resolution) was on average 3.2 degrees (range $0-78.8$ ), with slope being highest in the Northern part of Bonaire (Annex 2). Fraction vegetation cover per pixel (10 $\mathrm{m}$ resolution) was on average 0.22 (range $0-0.77$ ), with highest vegetation cover observed in the mangrove forest surrounding Lac bay in the South-East part of Bonaire (Annex 3). Erosion hazard per pixel (10 m resolution) ranged between 0 and 1 (Annex 4), with relatively high values for urban areas like Kralendijk, where vegetation cover is low. Mean erosion hazard per watershed was on average 0.74 (range 0.58-0.91), with highest values for watershed 21 (Annex 5). Note that we did not estimate mean erosion hazard for watersheds 64 to 69 as these watersheds mainly consisted of saltpans.

\subsection{Coral reef community composition}

At the lower terrace reef zone (5-7m), proportion coral cover was on average 0.14 (range $0-0.63$ ), while sand and algae cover was on average 0.28 (range $0-1$ ) and 0.45 (range $0-0.83$ ). Moreover, coral and algae cover showed a negative correlation with sand cover, while coral cover was positively correlated with algae cover (Fig. 4).

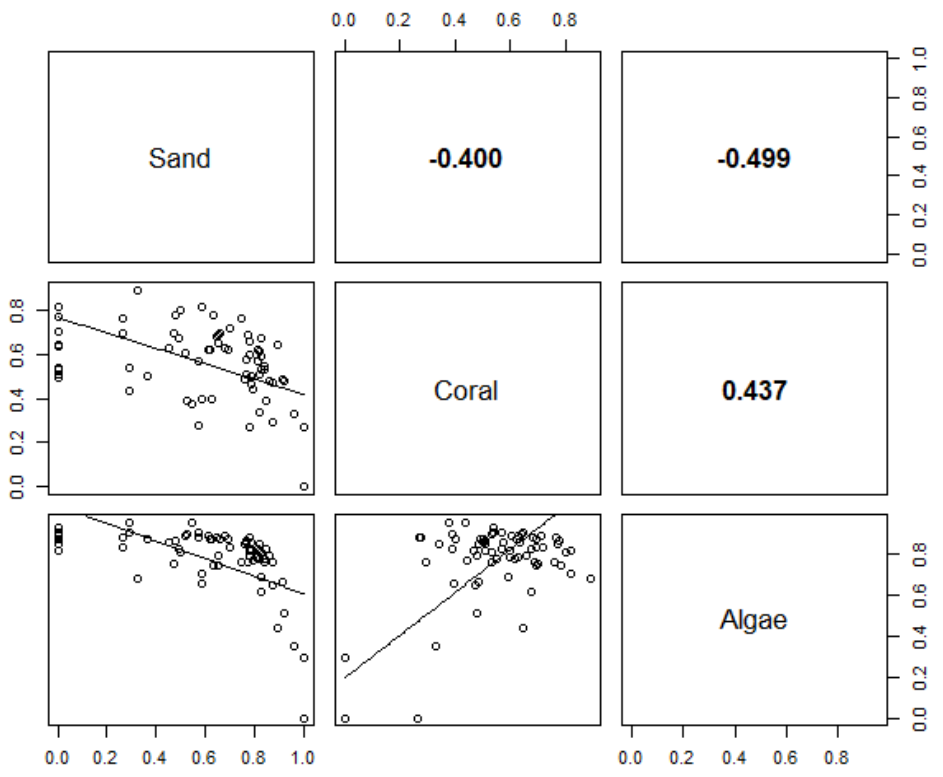

Fig. 4. Matrix of scatterplots (lower panel) and Pearson's coefficients (upper panel) of correlations between fourth-root-transformed proportion of coral cover, sand cover and algae cover at the lower terrace reef zone $(5-7 \mathrm{~m})$. Mean value per site were used for all variables $(N=71)$. Significant correlations are indicated with a reduced major axis regression line through data. Bold values represent significant correlations $(P<0.05)$.

At the upper drop-off zone (8-12m), proportion coral cover was on average 0.24 (range 0.005-0.52), while sand and algae cover was on average 0.13 (range 0-77) and 0.50 (range 0.18-0.79). Moreover, at this depth zone, coral cover showed a negative correlation with both sand cover and algae cover (Fig. 5). Coral cover was significantly lower in the lower terrace reef zone compared to the upper drop-off zone $\left(F_{1,140}=23.94, P<0.001\right.$, Adjusted $\left.R^{2}=0.14\right)$, which was also the case for algae cover 
$\left(F_{1,140}=6.43, P=0.012\right.$, Adjusted $\left.R^{2}=0.037\right)$. We found no effect of depth zone on proportion sand cover $\left(F_{1,140}=2.85, P=0.093\right.$, Adjusted $\left.R^{2}=0.013\right)$.

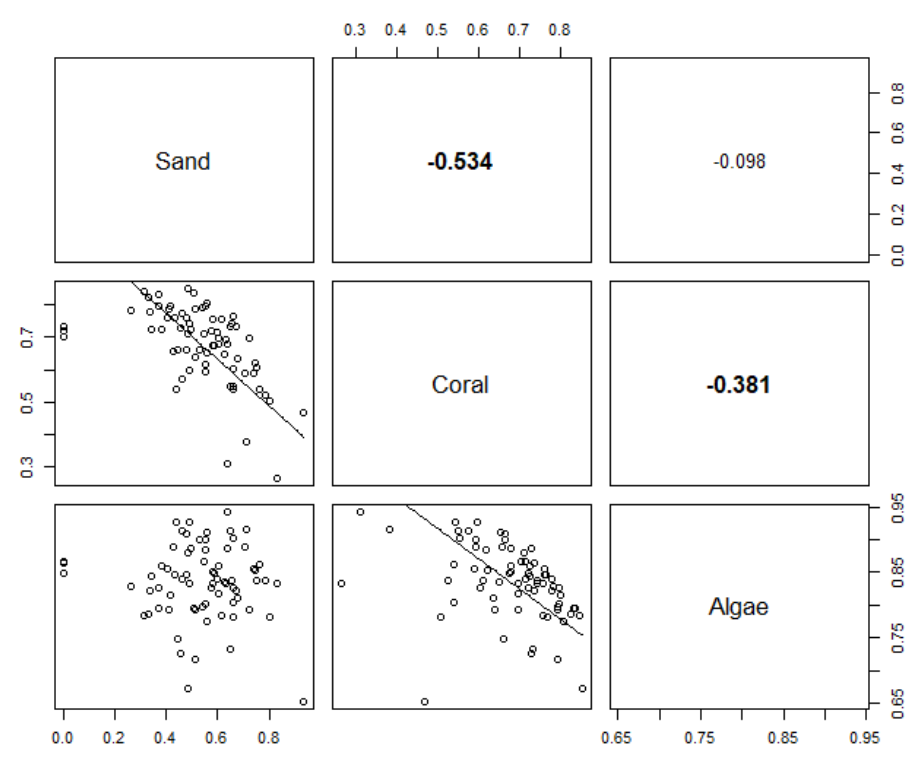

Fig. 5. Matrix of scatterplots (lower panel) and Pearson's coefficients (upper panel) of correlations between fourth-root-transformed proportion of coral cover, sand cover and algae cover at the upper drop-off zone (8-12 m). Mean value per site were used for all variables $(N=71)$. Significant correlations are indicated with a reduced major axis regression line through data. Bold values represent significant correlations $(P<0.05)$.

\subsection{Watershed-reef health relationship}

The most parsimonious model to account for variation in the proportion of coral cover (a proxy for coral reef health) at the lower terrace reef zone only included a negative effect of mean erosion hazard of the nearest upstream watershed (Table 1), and explained $17 \%$ of the variation in coral cover at this depth $\left(P<0.001\right.$, Adj. $\mathrm{R}^{2}=0.17$, Fig. 6; Table 2, Annex 6). Although the model including both mean erosion hazard in the nearest upstream watershed and surface area of the nearest upstream watershed as fixed effects was best supported (Table 1), it required an extra parameter without reducing $\mathrm{AIC}_{\mathrm{c}}$ by 2 points (Table 1 ). This implies that there is only limited support for an effect of surface area of the nearest upstream watershed on coral cover at the lower terrace reef zone (Burnham \& Anderson 2002).

At the upper drop-off zone, the most parsimonious model to account for variation in coral cover only included a positive effect of distance to the nearest upstream run-off point source (Table 1), which explained $12 \%$ of the variation in coral cover at this depth $\left(P<0.001, A d j . R^{2}=0.12\right.$, Fig. 7 , Table 2; Annex 7). Note that for the upper drop-off zone the model that included both mean erosion hazard of the nearest upstream watershed and distance to the nearest upstream run-off point as fixed effects was best supported (Table 1). However, as this model required an extra parameter without reducing AICc by 2 points (Table 1 ), there is only limited support for an effect of mean erosion hazard on coral cover at the upper drop-off zone (Burnham \& Anderson 2002).

The most parsimonious model to account for variation in the proportion of sand cover ( $a$ proxy for sediment run-off) at the lower terrace reef zone only included a positive effect of mean erosion hazard ( $P<0.001$, Fig. 6, Table $1 \& 2$ ), and explained $14 \%$ of the variation in sand cover at the lower terrace (Adj. $R^{2}=0.14$ ). At the upper drop-off zone, the most parsimonious model to account for variation in sand cover included a positive effect of mean erosion hazard $(P<0.01$, Fig. 6 , Table 1 
\& 2) and a negative effect of distance to the nearest upstream run-off point source $(P<0.001$, Fig. 7; Table $1 \& 2$ ) and explained $22 \%$ of the variation in sand cover at this depth (Adj. $R^{2}=0.22$ ).

At the lower terrace reef zone, the most parsimonious model to account for variation in the proportion of algae cover (a proxy for nutrient run-off) included a quadratic effect of mean erosion hazard $(P<0.001$, Fig. 6 ; Table $1 \& 2$ ), which explained $22 \%$ of the variation in algae cover at the lower terrace. At the upper drop-off zone, the most parsimonious model to account for variation in algae cover was the intercept model (Table $1 \& 2$ ). Parameter estimates for most parsimonious models are presented in Table 2.
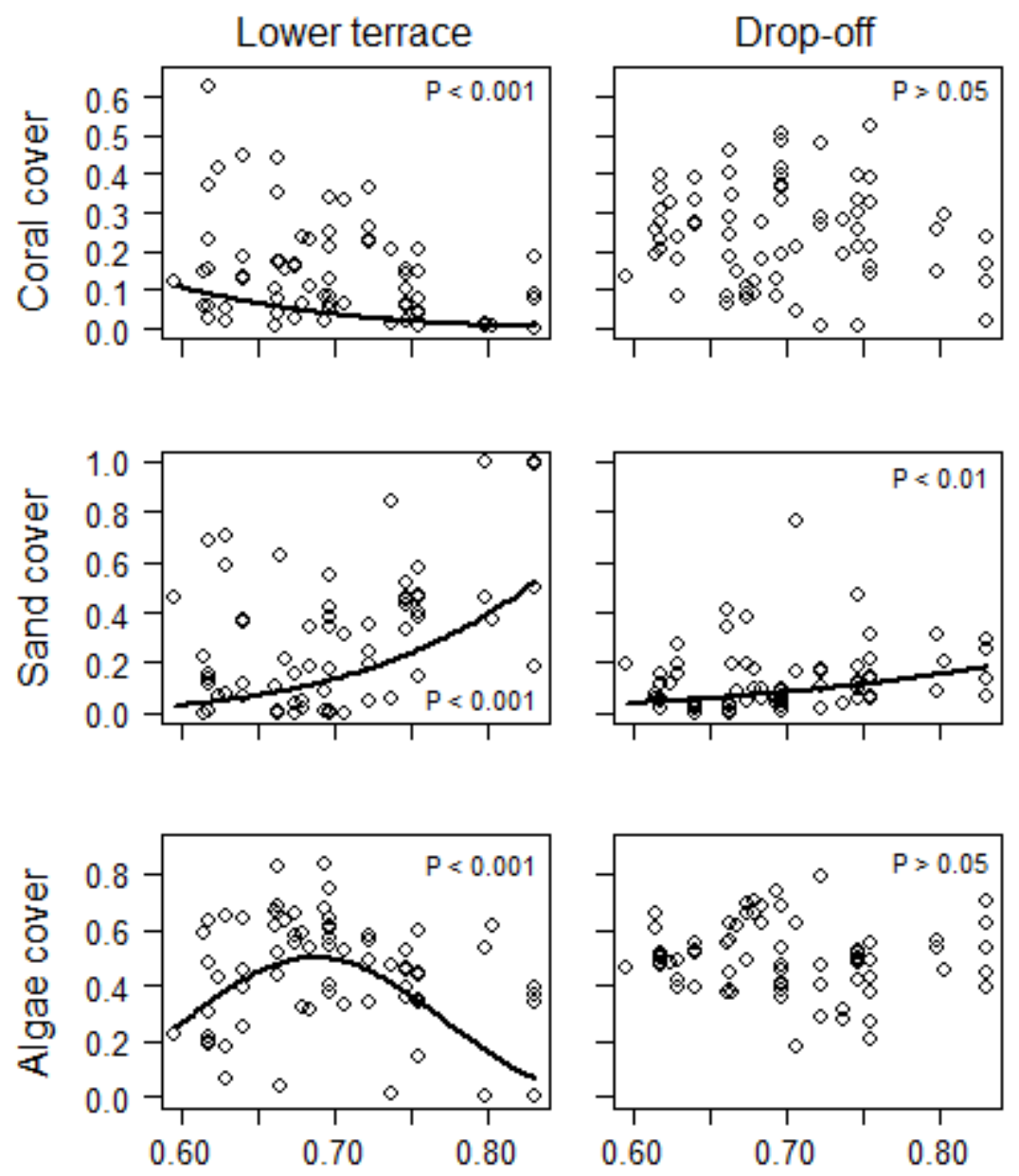

\section{Mean erosion hazard nearest upstream watershed}

Fig. 6. Effect of mean erosion hazard of the nearest upstream watershed on the proportion of coral, sand and algae cover at two depth zones (i.e. lower terrace and drop-off) at the leeward reef of Bonaire. Model fit is only plotted for significant effects $(P<0.05)$. Proportion cover was obtained by back-transforming the predicted fourth-root from the model. 


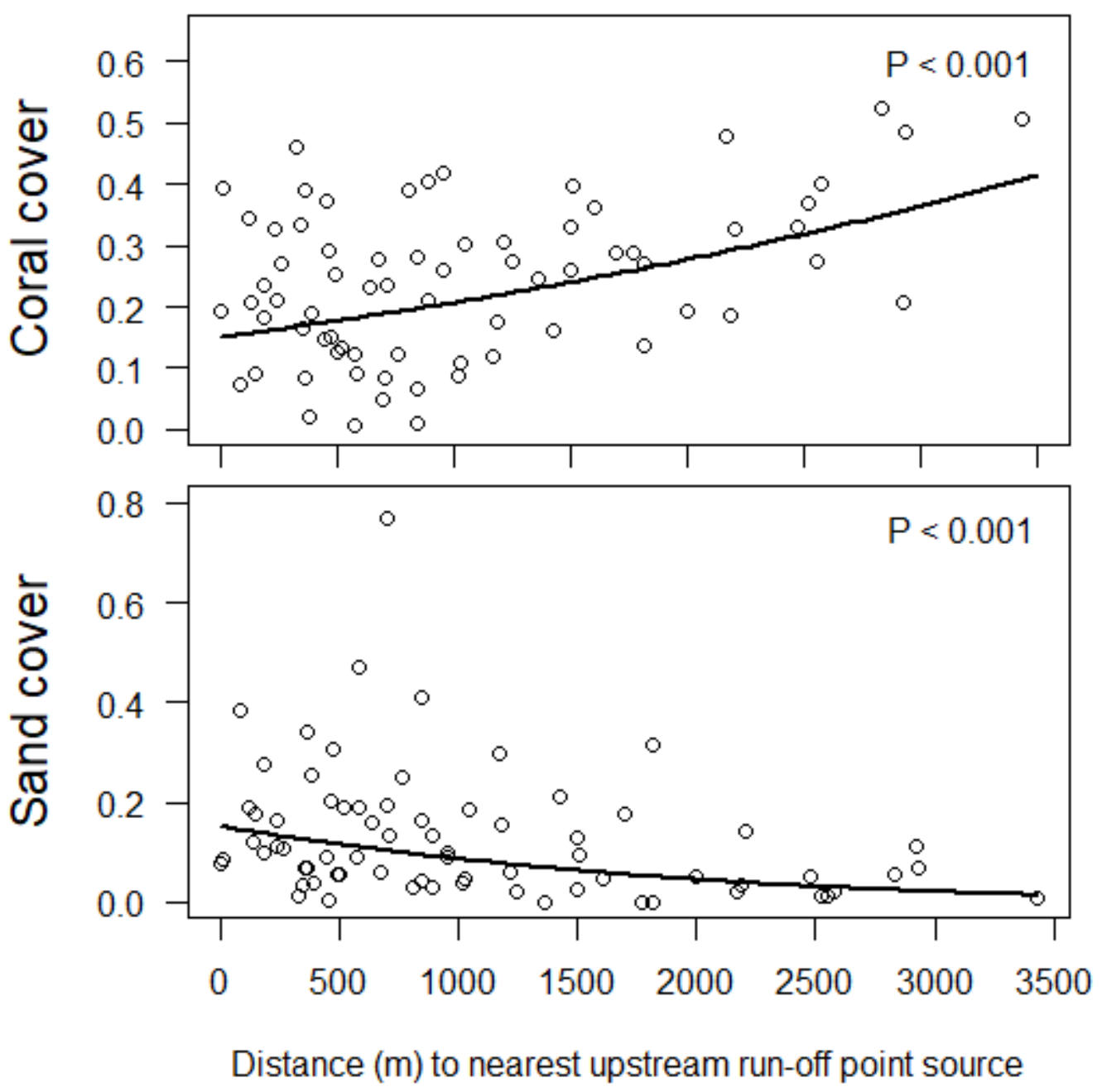

Fig. 7. Effect of distance $(m)$ to nearest upstream run-off point source on the proportion of coral cover (upper panel) and sand cover (lower panel) at the upper drop-off reef zone at the leeward reef of Bonaire. Line in plots represents to model fit. Proportion cover was obtained by back-transforming the predicted fourth-root from the model. 
Table 1. Model selection results for proportion of marine benthic cover (i.e. coral, sand or algae cover) as a function of mean erosion hazard of the nearest upstream watershed (e), surface area (ha) of the nearest upstream watershed $(a)$, distance $(m)$ to the nearest upstream run-off site (d), and in the case of algae cover, also the quadratic term of mean erosion hazard of the nearest upstream watershed $\left(\mathrm{e}^{2}\right)$ for the lower terrace reef zone (left panel) and the upper drop-off reef zone (right panel). The most parsimonious model is shown in bold. Only models with a model weight of $>0.03$ are shown. AIC : Akaike's information criterion adjusted for small sample size.

\begin{tabular}{|c|c|c|c|c|c|c|c|c|c|}
\hline \multicolumn{5}{|c|}{ Lower terrace reef zone } & \multicolumn{5}{|c|}{ Upper drop-off reef zone } \\
\hline Model & $\mathrm{df}$ & $\log \mathrm{Lik}$ & $\Delta \mathrm{AIC}_{\mathrm{c}}$ & weight & Model & $\mathrm{df}$ & logLik & $\Delta \mathrm{AIC}_{\mathrm{c}}$ & weight \\
\hline \multicolumn{5}{|l|}{ Coral cover } & \multicolumn{5}{|l|}{ Coral cover } \\
\hline$a+e$ & 4 & 33.9 & $0.00^{\mathrm{a}}$ & 0.47 & $d+e$ & 4 & 57.9 & $0.00^{d}$ & 0.30 \\
\hline$a+d+e$ & 5 & 34.3 & 1.58 & 0.21 & $\boldsymbol{d}$ & 3 & 56.7 & 0.24 & 0.26 \\
\hline e & 3 & 31.9 & 1.82 & 0.19 & $a+d$ & 4 & 57.7 & 0.33 & 0.25 \\
\hline$d+e$ & 4 & 32.6 & 2.51 & 0.13 & $a+d+e$ & 5 & 58.5 & 1.11 & 0.17 \\
\hline \multicolumn{5}{|l|}{ Sand cover } & \multicolumn{5}{|l|}{ Sand cover } \\
\hline e & 3 & -6.7 & $0.00^{b}$ & 0.48 & $d+e$ & 4 & 32.8 & $0.00^{e}$ & 0.59 \\
\hline$a+e$ & 4 & -6.4 & 1.59 & 0.22 & $a+d+e$ & 5 & 33.4 & 1.06 & 0.35 \\
\hline$d+e$ & 4 & -6.4 & 1.64 & 0.21 & $a+d$ & 4 & 30.1 & 5.46 & 0.04 \\
\hline$a+d+e$ & 5 & -6.2 & 3.52 & 0.08 & & & & & \\
\hline \multicolumn{5}{|l|}{ Algae cover } & \multicolumn{5}{|l|}{ Algae cover } \\
\hline$e+e^{2}$ & 4 & 30.4 & $0.00^{c}$ & 0.47 & intercept & 2 & 103.2 & $0.00^{f}$ & 0.22 \\
\hline$d+e+e^{2}$ & 5 & 30.8 & 1.45 & 0.23 & $d$ & 3 & 104.2 & 0.23 & 0.20 \\
\hline$a+e+e^{2}$ & 5 & 30.7 & 1.78 & 0.20 & $e$ & 3 & 103.6 & 1.37 & 0.11 \\
\hline \multirow[t]{7}{*}{$a+d+e+e^{2}$} & 6 & 31.0 & 3.48 & 0.08 & $d+e$ & 4 & 104.5 & 1.46 & 0.09 \\
\hline & & & & & $a$ & 3 & 103.2 & 1.78 & 0.08 \\
\hline & & & & & $a+d$ & 4 & 104.3 & 1.84 & 0.07 \\
\hline & & & & & $e+e^{2}$ & 4 & 104.2 & 2.17 & 0.06 \\
\hline & & & & & $d+e+e^{2}$ & 5 & 104.9 & 2.30 & 0.06 \\
\hline & & & & & $a+e$ & 4 & 103.7 & 3.49 & 0.04 \\
\hline & & & & & $a+d+e$ & 5 & 104.8 & 3.64 & 0.04 \\
\hline \multicolumn{5}{|c|}{${ }^{\mathrm{a}} \mathrm{AIC}_{\mathrm{c}}=-59.17 ;{ }^{\mathrm{b}} \mathrm{AIC} \mathrm{C}_{\mathrm{c}}=19.84 ;{ }^{\mathrm{c}} \mathrm{AIC} \mathrm{c}_{\mathrm{c}}=-52.17$} & \multicolumn{5}{|c|}{${ }^{\mathrm{d}} \mathrm{AIC}_{\mathrm{c}}=-107.21 ;{ }^{\mathrm{e}} \mathrm{AIC} \mathrm{C}_{\mathrm{c}}=56.98 ;{ }^{\mathrm{f}} \mathrm{AIC} \mathrm{C}_{\mathrm{c}}=-202.25$} \\
\hline
\end{tabular}


Table 2. Parameter estimates, standard errors (SE), $t$-values, and $P$-values for most parsimonious models (see Table 1 ) including the effects of mean erosion hazard of the nearest upstream watershed, distance $(\mathrm{m})$ to the nearest upstream run-off site, and in the case of algae cover, the quadratic term of mean erosion hazard of the nearest upstream watershed on proportion of marine benthic cover (i.e. coral, sand or algae cover) for the lower terrace reef zone (left panel) and the upper drop-off reef zone (right panel). Significant $P$-values are shown in bold.

\begin{tabular}{|c|c|c|c|c|c|c|c|c|c|}
\hline \multicolumn{5}{|c|}{ Lower terrace reef zone } & \multicolumn{5}{|c|}{ Upper drop-off reef zone } \\
\hline Coral cover & Estimate & SE & $t$-value & $P$ & Coral cover & Estimate & SE & $t$-value & $P$ \\
\hline Intercept & 1.37 & 0.21 & 6.48 & $<0.001$ & Intercept & 0.62 & 0.02 & 29.33 & $<0.001$ \\
\hline Mean erosion hazard & -1.17 & 0.30 & -3.87 & $<0.001$ & Distance to run-off & 0.0001 & 0.00 & 3.25 & $<0.001$ \\
\hline Sand cover & & & & & Sand cover & & & & \\
\hline Intercept & -0.70 & 0.36 & -1.91 & 0.06 & Intercept & -0.001 & 0.21 & -0.01 & 0.99 \\
\hline \multirow[t]{2}{*}{ Mean erosion hazard } & 1.86 & 0.52 & 3.58 & $<0.001$ & Mean erosion hazard & 0.90 & 0.30 & 2.98 & $<0.01$ \\
\hline & & & & & Distance to run-off & -0.0001 & 0.00 & -3.71 & $<0.001$ \\
\hline Algae cover & & & & & Algae cover & & & & \\
\hline Intercept & -6.72 & 2.25 & -2.98 & $<0.01$ & Intercept & 0.84 & 0.01 & 123.50 & $<0.001$ \\
\hline Mean erosion hazard & 22.02 & 6.34 & 3.48 & $<0.001$ & & & & & \\
\hline Mean erosion hazard ${ }^{2}$ & -16.0 & 4.4 & -3.62 & $<0.001$ & & & & & \\
\hline
\end{tabular}




\section{Discussion}

Declining coastal water quality, as a result of land-based run-off is recognized as one of the most significant local threats to coral reef diversity and resilience worldwide (Bartley et al. 2014, Risk 2014, Carlson et al. 2019). As land-based run-off can be altered by changes in land use, the need to couple land-sea planning for effective coral reef conservation is now widely acknowledged (Carlson et al. 2019, Richmond et al. 2019). Yet, effective watershed-to-reef management requires improved understanding of land-sea linkages to simultaneously evaluate the effects of terrestrial and marine drivers on coral reefs, mediated by anthropogenic activities (Delevaux et al. 2018). In this study we contribute to this understanding by assessing the relationship between watershed-specific erosion hazard (a proxy for land-based run-off) and composition of the coral reef community at Bonaire.

Coral cover (a proxy for coral reef health) at the lower terrace reef zone $(5-7 \mathrm{~m})$ showed a negative relationship with mean erosion hazard of the nearest upstream watershed, but no effect was found at the upper-drop-off zone (8-12 m). These results imply that hard corals living at the shallow reef are suffering more from the impact of land-based run-off from the nearest upstream watershed, compared to hard corals living at the upper drop-off zone. As the upper drop-off zone is further away from the terrestrial run-off point source compared to the lower terrace reef zone, this may have weakened the effect of mean erosion hazard of the nearest upstream watershed on coral cover at this depth zone. Stronger water currents at the upper drop-off zone, causing stronger water mixing and subsequent dilution of terrestrial run-off of sediment and nutrients, may also have weakened the negative relationship between mean erosion hazard and coral cover at this depth zone. Due to enhanced water currents, the upper drop-off zone may have received land-based run-off from several watersheds, making it more difficult to relate coral cover at the upper drop-off zone to mean erosion hazard in the nearest upstream watershed. More support for this notion comes from the positive relationship between mean erosion hazard and sand cover (a proxy for sediment run-off), which was significant for both depth zones, but stronger for the lower terrace zone compared to the upper dropoff zone (Fig. 6). Likewise, we found a small but significant quadratic effect of mean erosion hazard on algae cover (a proxy for nutrient run-off) at the lower terrace reef zone, but no such effect at the upper drop-off zone. This result may indicate land-based nutrient run-off stimulated algae growth at the shallow reef up to a threshold level (i.e. mean erosion hazard of $\sim 0.68$; Fig. 6), after which landbased run-off had a negative effect on macroalgae cover, presumably due to reduced light conditions (see Fig. 6).

In addition to the positive relationship between sand cover and mean erosion hazard at the upper drop-off zone, the negative impact of land-based run-off on coral reef health at the deeper reef was also indicated by the positive relationship between coral cover and distance to the nearest upstream terrestrial run-off point and the negative relationship between sand cover and distance to the nearest upstream terrestrial run-off point at this depth zone (Fig. 7).

Overall, coral, sand and algae cover were either impacted by erosion hazard of the nearest upstream watershed and/or by distance to the nearest upstream watershed, thus highlighting the importance of watershed characteristics (i.e. vegetation cover and slope) to overall coral reef health on Bonaire. Our results therefore indicate the need for a "watershed-to-reef" based coastal management approach that integrates terrestrial and marine conservation to preserve the coral reefs of Bonaire. As suggested by Roberts et al. (2017), coral reef managers could improve coral reef health by taking steps to reduce grazing pressures or by setting up revegetation programmes to increase vegetation cover in watersheds that are prone to soil erosion. However, apart from land-based run-off and associated soil erosion, the influences of other local, regional and global factors should also be accounted for when applying such a "watershed-to-reef" model to management decisions. 


\subsection{Methodological aspects}

In this study we used a DEM with 10-m resolution. As such, our estimation of watershed-specific erosion hazard could be improved by using a more detailed DEM with higher resolution. Moreover, while the effect of soil type on soil erosion is widely recognized (Roberts et al. 2017 and references therein), we did not account for the effect of variability in soil type when estimating watershed-specific erosion hazard on Bonaire. Future research aimed at identifying soil types across Bonaire, would therefore greatly benefit the accuracy of model estimations of watershed-specific run-off of sediments and nutrients. While hard coral cover is regarded as a reliable indicator of coral reef health, recent research efforts have recognized the added value of regarding species-specific life-history traits such as accretion rates and colony morphology when assessing the functional and ecological status of coral reefs (González-Barrios \& Álvarez-Filip 2018, de Bakker et al. 2019). Most opportunistic coral species are relatively stress tolerant, yet they lack the capacity to maintain the structural framework necessary to support ecological functioning and biodiversity (de Bakker et al. 2019). Therefore, we encourage future studies to explore the relationship between watershed-specific properties and other metrics for coral reef health.

\subsection{Conclusion and recommendations}

The economy of Bonaire is for a large part dependent on dive tourism, which makes conservation of the reef a key priority for the local government and diving industry. So far, coral reef conservation on Bonaire has largely focussed on marine-based actions, with the exception of the creation of a sewage treatment plant. In this study we provide field-based evidence for a direct relationship between watershed-specific erosion hazard and coral reef health. This suggests that reef managers could improve coral reef health through engaging in "watershed-to-reef" based erosion control (e.g. controlling of grazing intensity, replanting of natural vegetation). The "watershed-to-reef" models presented in this report provide reef managers on Bonaire with tools to estimate impacts that actions to reduce erosion hazard in watersheds will have on coral cover. Our models will thus allow managers to compare alternative watershed-specific management options for their effectiveness. In addition, having identified watersheds that are more prone to erosion hazard than others will contribute to more efficient allocation of the limited resources available for terrestrial and coral reef conservation. Our findings highlight the need for a nature-inclusive "watershed-to-reef" based coastal management approach that integrates terrestrial and marine conservation to preserve the island's valuable coral reef and related ecosystem services. 


\section{Acknowledgements}

We want to extend our gratitude to Didier de Bakker, Sil Piek, Yun Scholten, Sarah Veillat and Roger Meijs for their efforts in collecting the benthic cover data. We sincerely thank C. Eckrich for her support in the field. We also acknowledge the invaluable logistical assistance of the STINAPA Bonaire National Parks Foundation. Finally, we are very grateful to Oscar Bos for his valuable review. 


\section{Quality Assurance}

Wageningen Marine Research utilises an ISO 9001:2015 certified quality management system. This certificate is valid until 15 December 2021. The organisation has been certified since 27 February 2001. The certification was issued by DNV GL. 


\section{References}

Álvarez-Romero JG, Pressey RL, Ban NC, Vance-Borland K and others (2011) Integrated Land-Sea Conservation Planning: The Missing Links. Annual Review of Ecology, Evolution, and Systematics 42:381-409

Álvarez-Romero JG, Wilkinson SN, Pressey RL, Ban NC, Kool J, Brodie J (2014) Modeling catchment nutrients and sediment loads to inform regional management of water quality in coastal-marine ecosystems: A comparison of two approaches. Journal of Environmental Management 146:164-178

Bartley R, Bainbridge ZT, Lewis SE, Kroon FJ and others (2014) Relating sediment impacts on coral reefs to watershed sources, processes and management: A review. Science of The Total Environment 468469:1138-1153

Borst L, De Haas SA (2005) Hydrological research Bonaire; a hydrogeological investigation of Bonaire's watersystem. Amsterdam: Acacia institute.

Burnham KP, Anderson DR (2002) Model selection and multimodel inference: A practical informationtheoretic approach. Springer-Verlag, New York, NY

Carlson RR, Foo SA, Asner GP (2019) Land Use Impacts on Coral Reef Health: A Ridge-to-Reef Perspective. Frontiers in Marine Science 6

de Bakker DM, van Duyl FC, Bak RP, Nugues MM, Nieuwland G, Meesters EH (2017) 40 Years of benthic community change on the Caribbean reefs of Curaçao and Bonaire: the rise of slimy cyanobacterial mats. Coral Reefs 36:355-367

de Bakker DM, van Duyl FC, Perry CT, Meesters EH (2019) Extreme spatial heterogeneity in carbonate accretion potential on a Caribbean fringing reef linked to local human disturbance gradients. Global Change Biology 25:4092-4104

Delevaux JMS, Whittier R, Stamoulis KA, Bremer LL and others (2018) A linked land-sea modeling framework to inform ridge-to-reef management in high oceanic islands. PLOS ONE 13:e0193230

Fabricius KE (2005) Effects of terrestrial runoff on the ecology of corals and coral reefs: review and synthesis. Marine Pollution Bulletin 50:125-146

Freitas Jd, Nijhof BSJ, Rojer AC, Debrot AO (2005) Landscape ecological vegetation map of the island of Bonaire (southern Caribbean). Caribbean Research and Management of Biodiversity Foundation; Royal Netherlands Acadamy of Arts and Sciences, Willemstad, Amsterdam

González-Barrios FJ, Álvarez-Filip L (2018) A framework for measuring coral species-specific contribution to reef functioning in the Caribbean. Ecological Indicators 95:877-886

Hoegh-Guldberg O, Mumby PJ, Hooten AJ, Steneck RS and others (2007) Coral Reefs Under Rapid Climate Change and Ocean Acidification. Science 318:1737-1742

Hughes TP, Baird AH, Bellwood DR, Card M and others (2003) Climate change, human impacts, and the resilience of coral reefs. Science 301:929-933

Hughes TP, Barnes ML, Bellwood DR, Cinner JE and others (2017) Coral reefs in the Anthropocene. Nature 546:82-90

Kennedy Emma V, Perry Chris T, Halloran Paul R, Iglesias-Prieto R and others (2013) Avoiding Coral Reef Functional Collapse Requires Local and Global Action. Current Biology 23:912-918

Klein CJ, Ban NC, Halpern BS, Beger M and others (2010) Prioritizing Land and Sea Conservation Investments to Protect Coral Reefs. PLoS ONE 5:1-8

Klein CJ, Jupiter SD, Watts M, Possingham HP (2014) Evaluating the influence of candidate terrestrial protected areas on coral reef condition in Fiji. Marine Policy 44:360-365

Moberg F, Folke C (1999) Ecological goods and services of coral reef ecosystems. Ecological Economics 29:215-233

Mücher S, Suomalainen J, Stuiver J, Meesters E (2017) Hyperspectral Coral Reef Classification of Bonaire. Wageningen Marine Research, Den Helder

Oleson KLL, Falinski KA, Lecky J, Rowe C and others (2017) Upstream solutions to coral reef conservation: The payoffs of smart and cooperative decision-making. Journal of Environmental Management 191:8-18

Richmond RH, Golbuu Y, Shelton AJ (2019) Chapter 26 - Successful Management of Coral Reef-Watershed Networks. In: Wolanski E, Day JW, Elliott M, Ramachandran R (eds) Coasts and Estuaries. Elsevier

Risk MJ (2014) Assessing the effects of sediments and nutrients on coral reefs. Current Opinion in Environmental Sustainability 7:108-117

Roberts M, Hanley N, Williams S, Cresswell W (2017) Terrestrial degradation impacts on coral reef health: Evidence from the Caribbean. Ocean \& Coastal Management 149:52-68 
Rodgers KuS, Kido MH, Jokiel PL, Edmonds T, Brown EK (2012) Use of Integrated Landscape Indicators to Evaluate the Health of Linked Watersheds and Coral Reef Environments in the Hawaiian Islands. Environmental Management 50:21-30

Roos PJ (1971) The Shallow-Water Stony Corals of the Netherlands Antilles. Studies on the Fauna of Curaçao and other Caribbean Islands 37:1 - 108

Scheffer M, Barrett S, Carpenter SR, Folke C and others (2015) Creating a safe operating space for iconic ecosystems. Science 347:1317-1319

Stoms DM, Elizabeth MPM, Davis FW, Andelman SJ and others (2005) Integrated Coastal Reserve Planning: Making the Land-Sea Connection. Frontiers in Ecology and the Environment 3:429-436

Webster PJ, Holland GJ, Curry JA, Chang H-R (2005) Changes in Tropical Cyclone Number, Duration, and Intensity in a Warming Environment. Science 309:1844-1846 


\section{Justification}

Report C055/20

Project Number: 4318300121, KB36 Nature Inclusive Transitions

The scientific quality of this report has been peer reviewed by a colleague scientist and a member of the Management Team of Wageningen Marine Research

Approved: $\quad$ Oscar Bos

Senior researcher

Signature:

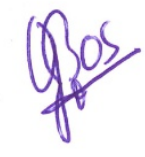

Date: $\quad$ 19th of June 2020

Approved: Drs. J. Asjes

Management Team member - Integration

Signature:

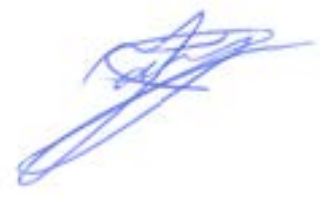

Date:

24th of June 2020 
Wageningen Marine Research

T +31(0)317480900

E: marine-research@wur.nl

www.wur.eu/marine-research

Visitors' address

- Ankerpark 271781 AG Den Helder

- Korringaweg 7, 4401 NT Yerseke

- Haringkade 1, 1976 CP IJmuiden
With knowledge, independent scientific research and advice, Wageningen Marine Research substantially contributes to more sustainable and more careful management, use and protection of natural riches in marine, coastal and freshwater areas.

Wageningen Marine Research is part of Wageningen University \& Research. Wageningen University \& Research is the collaboration between Wageningen University and the Wageningen Research Foundation and its mission is: 'To explore the potential for improving the quality of life' 


\section{Annex 1 Identified watersheds, water flows, and run-off sites into the sea for Bonaire based on DEM}

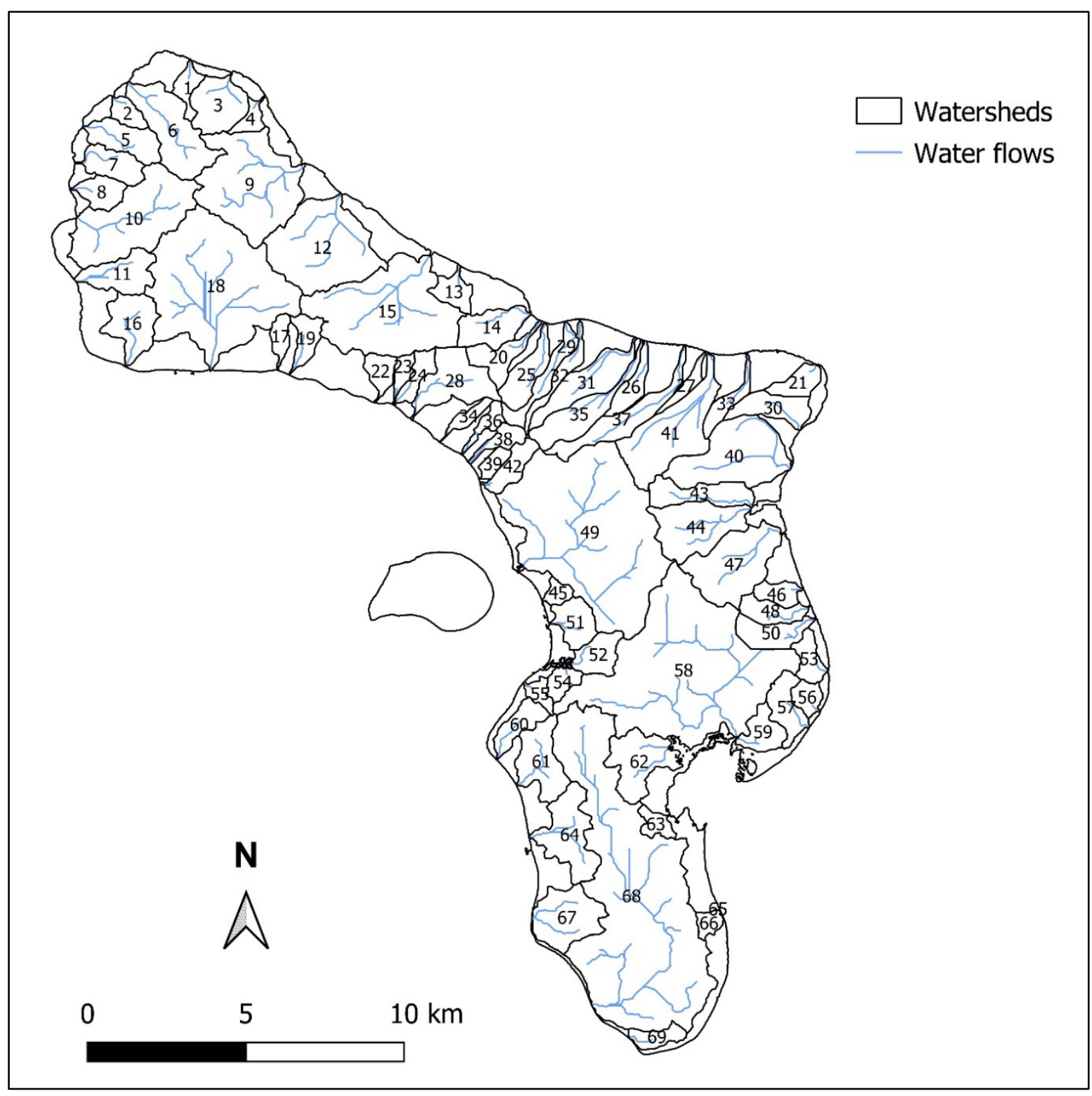




\section{Annex 2 Slope (in degrees) per pixel (10 $m$ resolution) for Bonaire based on DEM}

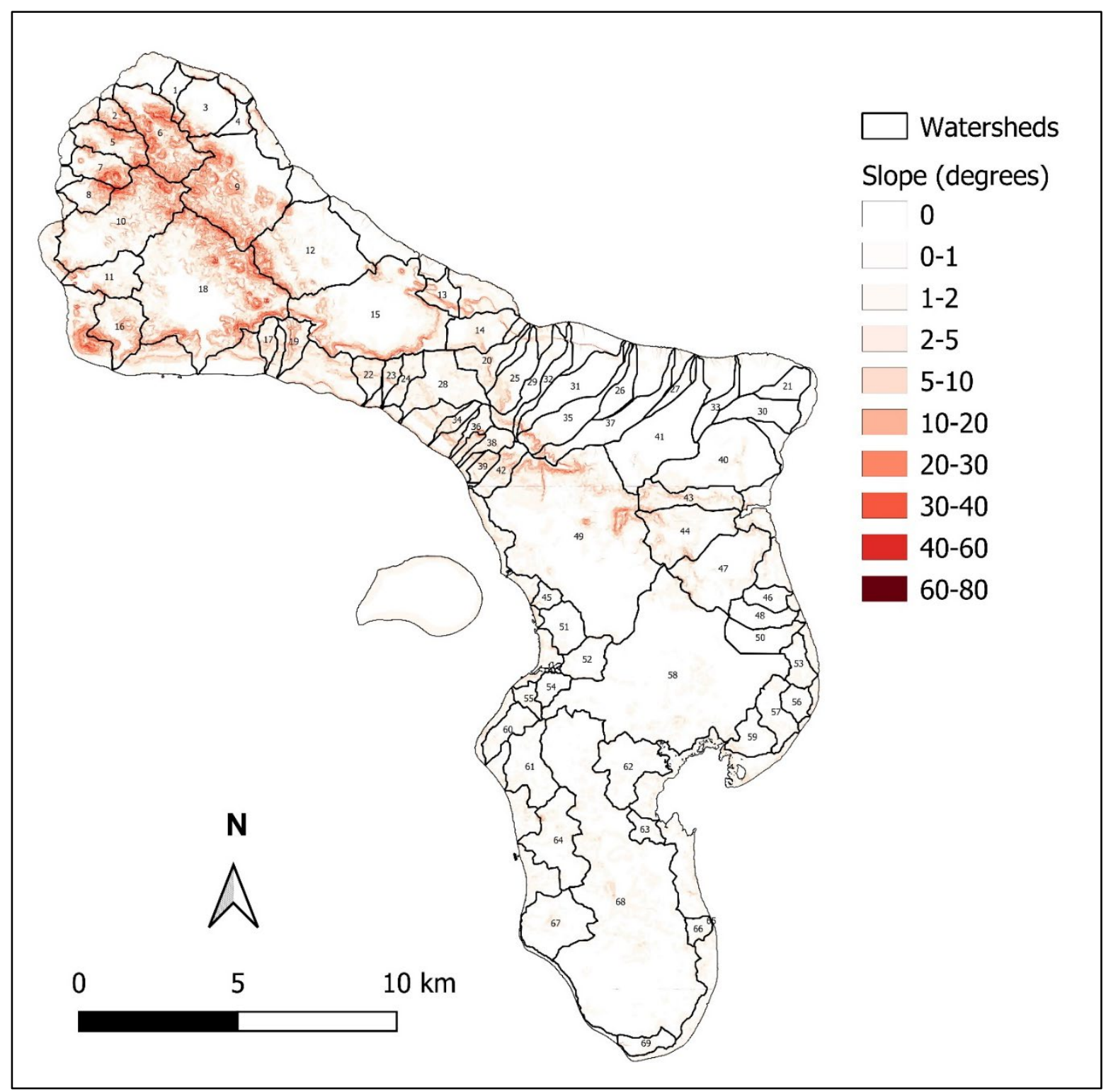




\section{Annex 3 Fraction vegetation ground cover per pixel ( $10 \mathrm{~m}$ resolution) for Bonaire, based on MVC-NDVI}

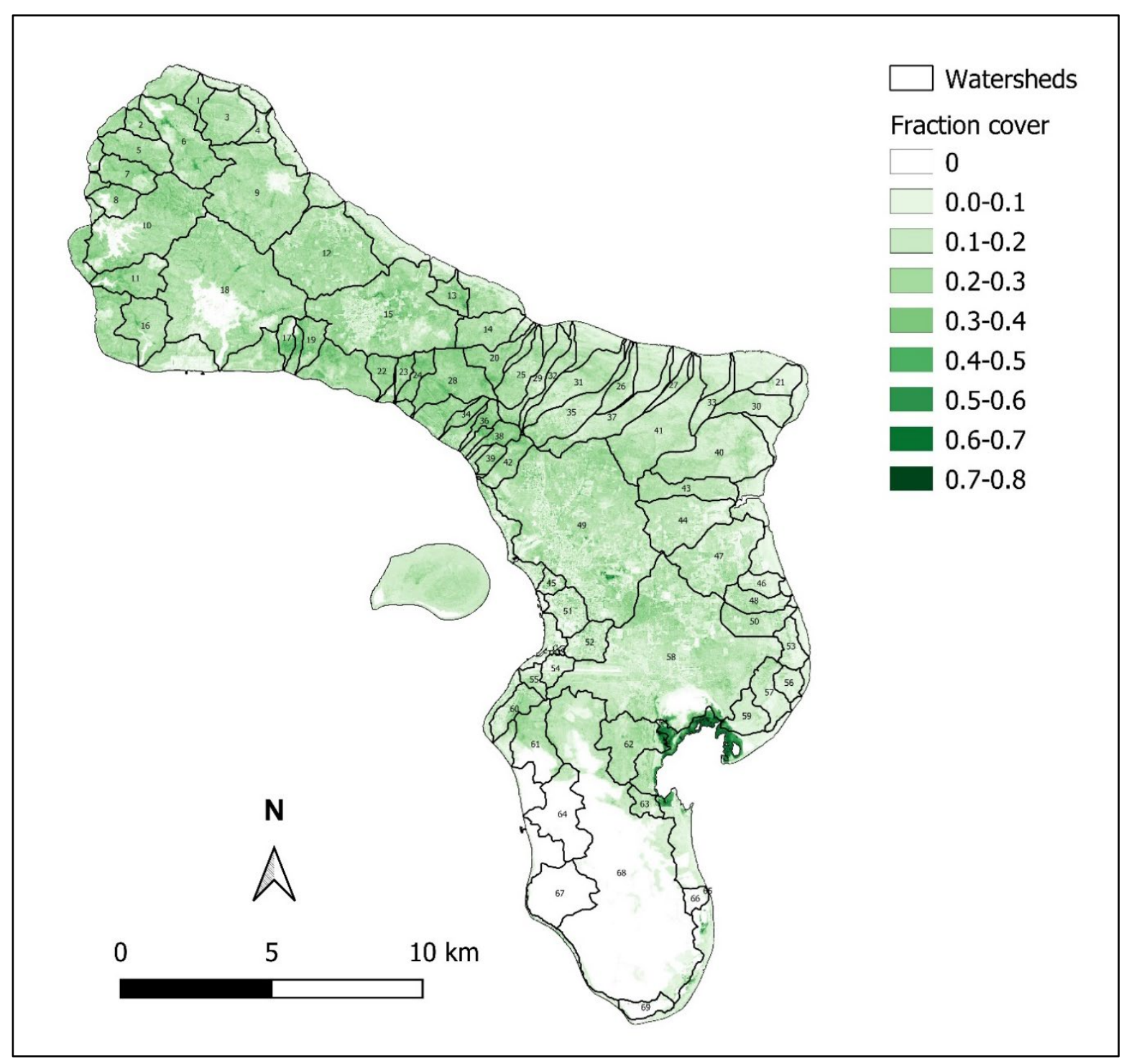




\section{Annex 4 Erosion hazard per pixel (10m resolution) for Bonaire}

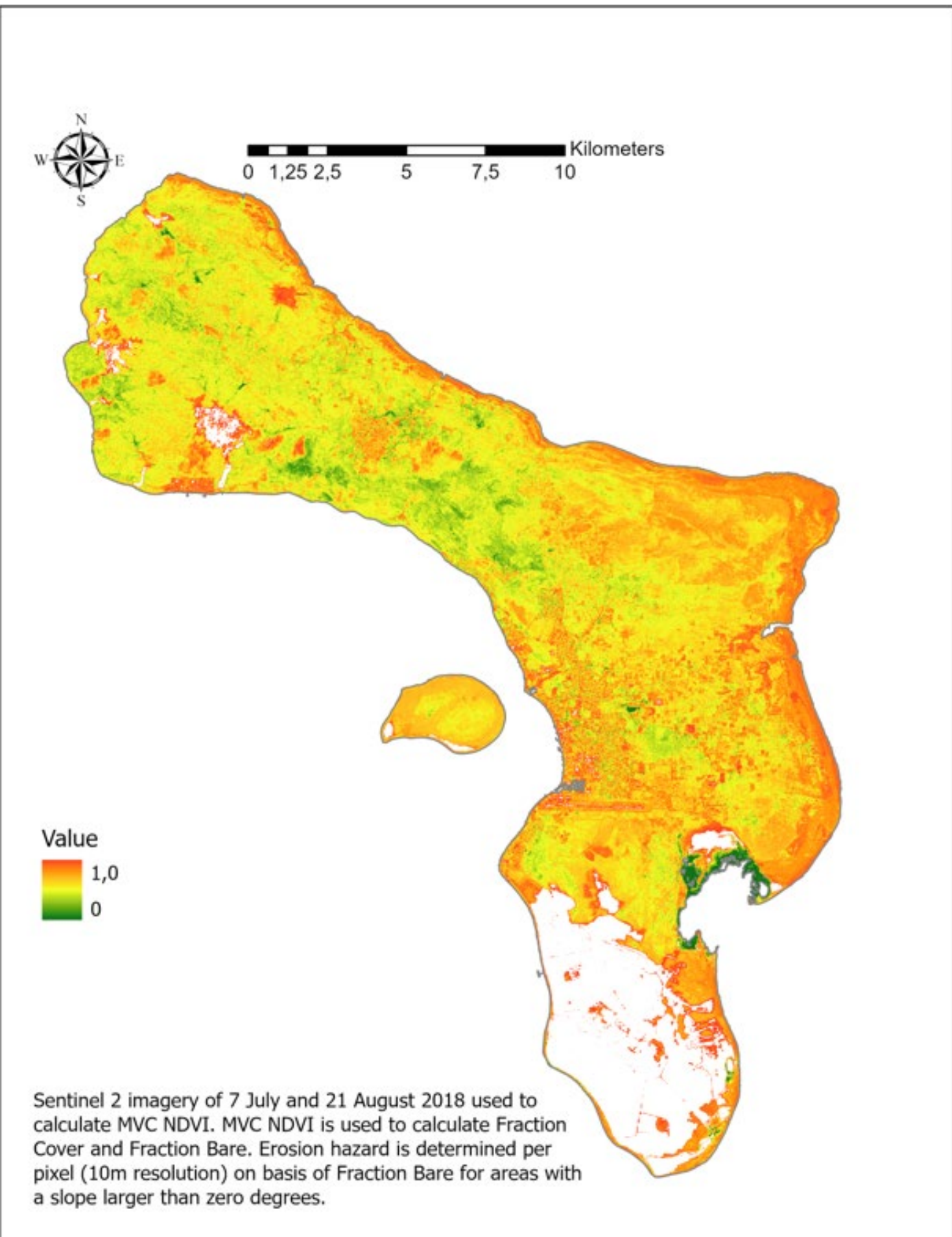




\section{Annex 5 Mean erosion hazard per watershed for Bonaire}

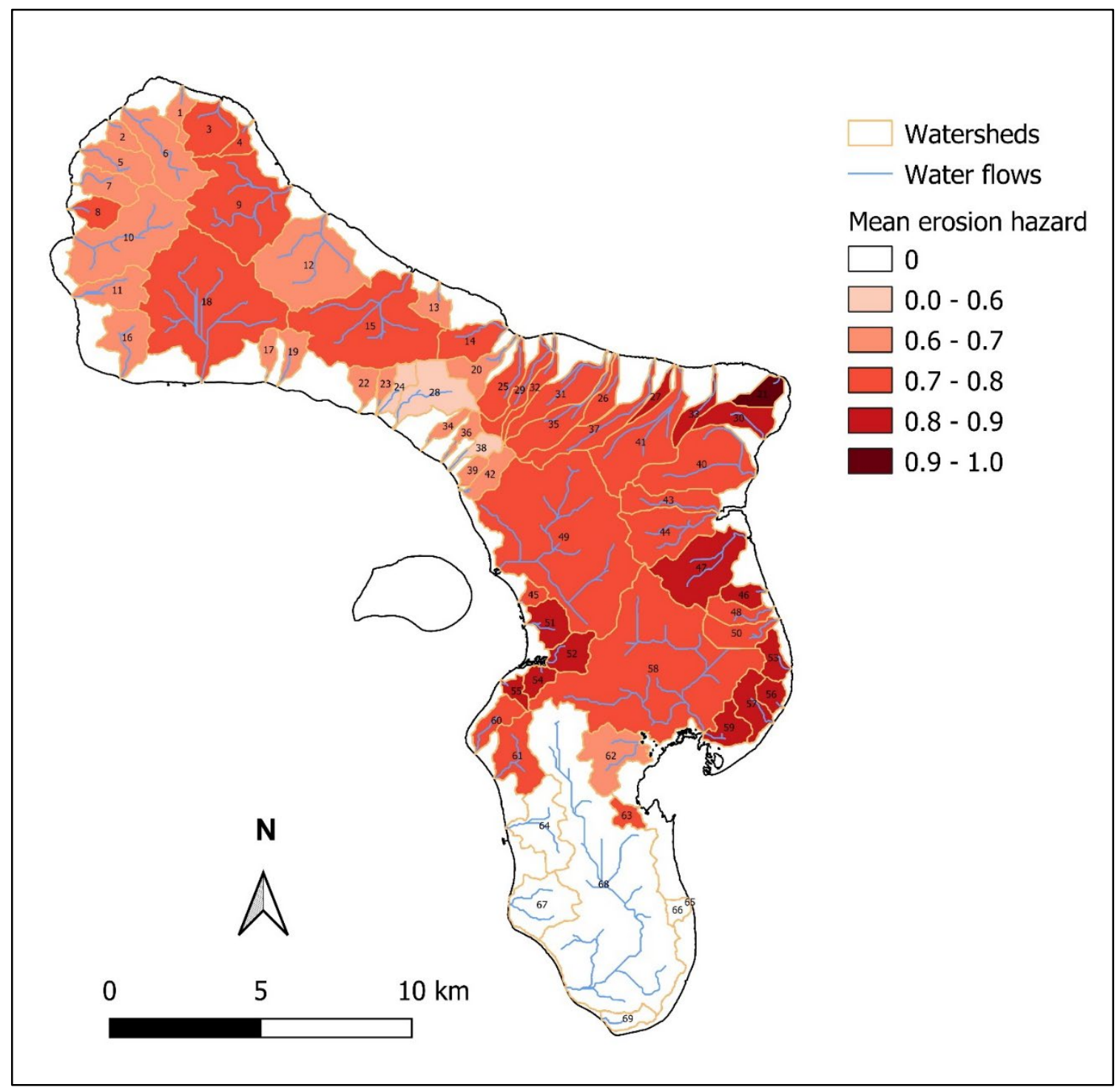

Mean erosion hazard was not determined for watersheds 64-69, as these watersheds mainly consisted of saltpans 


\section{Annex 6 Percentage coral cover at the lower terrace reef zone at the leeward reef of Bonaire in relation to watershed-specific mean erosion hazard and water flows}

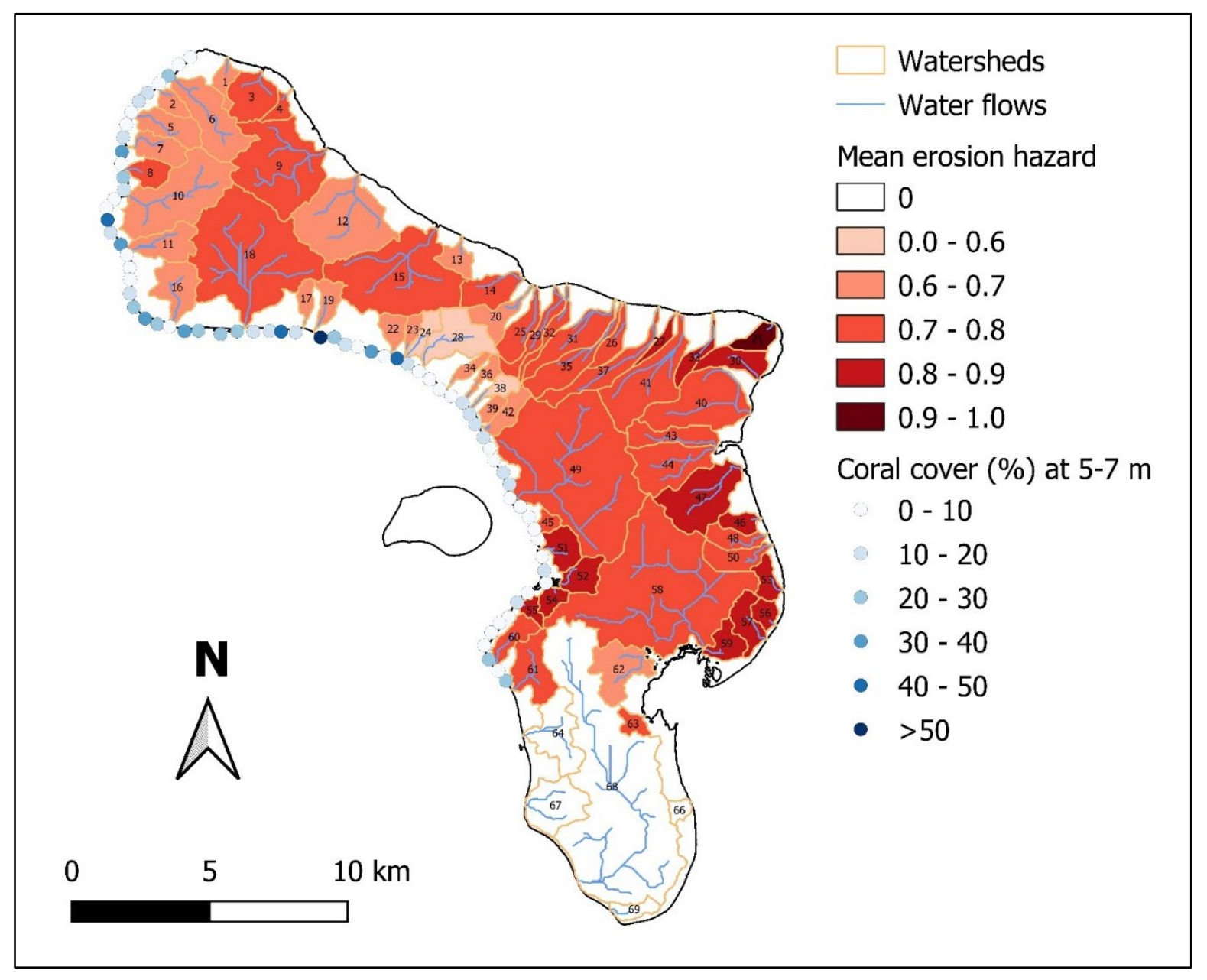


Annex 7 Percentage coral cover at the upper drop-off reef zone at the leeward reef of Bonaire in relation to watershedspecific mean erosion hazard and water flows

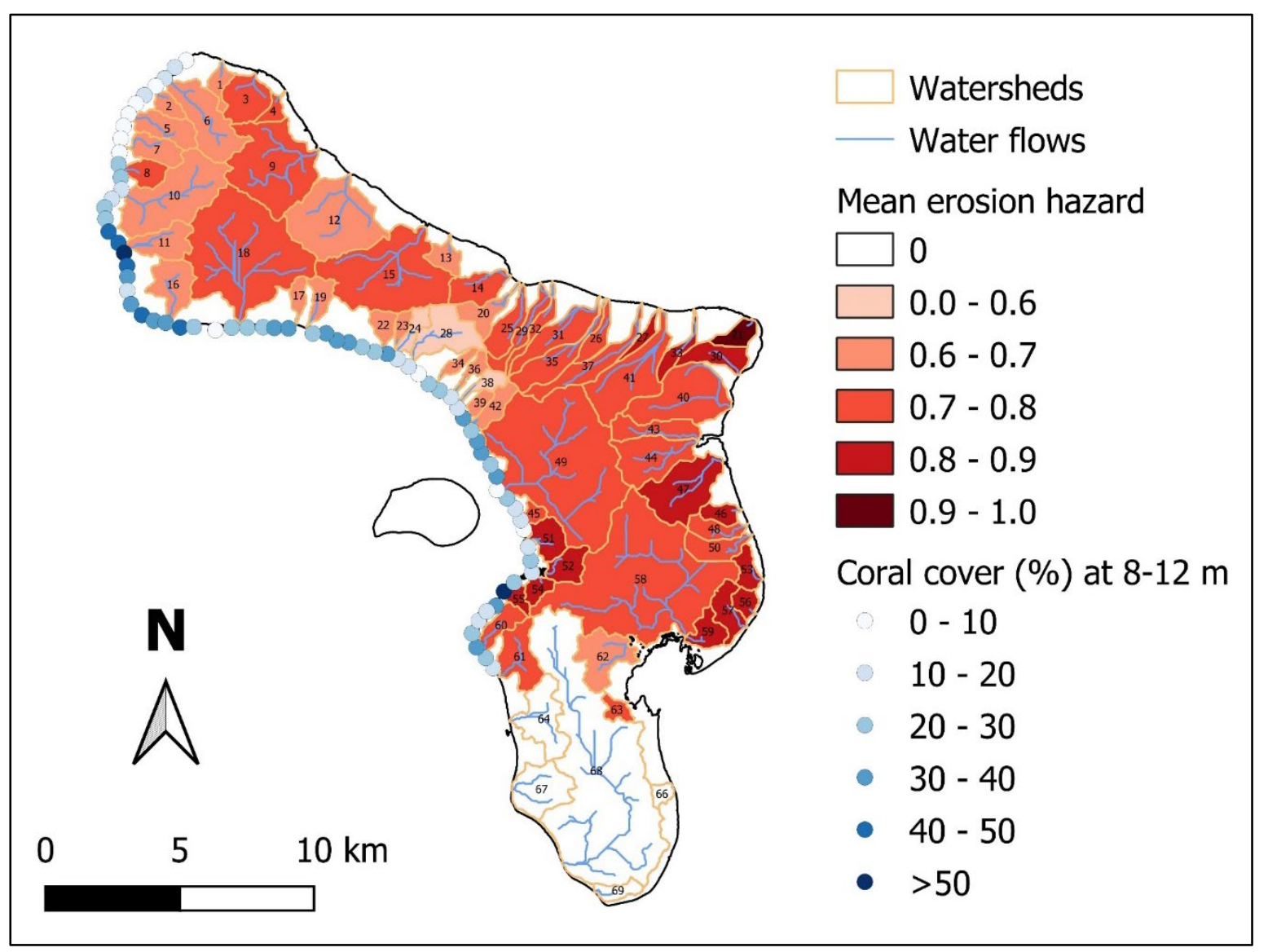

